\title{
Human infection due to the hedgehog fungus, Trichophyton mentagrophytes var. erinacei
}

\author{
R. A. QUAIFE \\ From the Public Health Laboratory, Portsmouth
}

SYNOPSIS Three human cases of skin infection caused by Trichophyton mentagrophytes var. erinacei are recorded. A review of work on the incidence and ecology in hedgehogs and as a source of human infection is given. It is suggested that a true increase in human infections is occurring. A description of the colonial and microscopical appearance of the fungus and their variance with other T. mentagrophytes varieties is discussed. The name Trichophyton erinacei is proposed as being taxonomically more correct.

Trichophyton mentagrophytes var. erinacei, first described by Marples and Smith in 1960, has been isolated in this laboratory during the past six months from three human cases of skin infection.

Work in the United Kingdom and New Zealand by Marples and Smith (1960), English, Evans, Hewitt, and Warin (1962), La Touche and Forsier (1963), Smith and Marples (1963), English, Smith, and Rush-Munro (1964), and English (1964) has established the incidence and ecology of $T$. mentagrophytes var. erinacei in hedgehogs and as a source of human infections. English et al. (1962) recorded ringworm of man caused by a variety of Trichophyton mentagrophytes which was associated with the handling of hedgehogs in the Bristol area. Only one previous record from Britain exists in which a dermatophyte infection was directly linked with the handling of hedgehogs (Eddowes, 1898), but the organism was not cultivated.

Smith and Marples (1963) state that in the Dunedin area of New Zealand since $T$. mentagrophytes var. erinacei was first recognized, it has been more frequently isolated from human infections than either T. mentagrophytes var. granulare or Trichophyton verrucosum which are the two other zoophilic Trichophyton species regularly isolated in the area. Dr. I. G. Murray (verbal report) quotes six human cases in 1964 and three in the first half of 1965 in the United Kingdom from which cultures were sent to the Mycological Reference Laboratory, three of these being recorded in this report. Though the recognition of the fungus as a human pathogen may account for some of the increase in reported isolations, it is Received for publication 5 August 1965. suggested that there may also be a true increase. In all three cases in this report, direct microscopical examination showed the presence of fungus, and all six inoculations of skin scrapings on Sabouraud's medium, with and without added chloramphenicol and cycloheximide, produced from each case a bright yellow or yellow-orange pigmented colony with finely granular surface and microscopically showing Trichophyton type macroconidia and large numbers of microconidia. Had this occurred previously, an atypical Trichophyton mentagrophytes type fungus would have been considered, as indeed the first isolated strain was initially designated.

\section{SOURCES OF INFECTION}

English (1964) states that there are two sources of infection in man, and her description follows.

'DIRECT INFECTION That clinically normal hedgehogs can harbour $T$. mentagrophytes var. erinacei is clear from this survey. It should therefore be emphasized to the public, and especially to children, that the handling of any hedgehog, even if apparently perfectly healthy, brings a risk of contracting hedgehog ringworm. Though it has been shown that Microsporum distortum and the granular form of T. mentagrophytes can both survive on the hedgehog, survey results indicate that there is virtually no risk to man of contracting such infections from this source.

INDIRECT INFECTION The results of the soil inoculation experiments seem to eliminate as a probability the soil-borne infection of man by $T$. mentagrophytes 
var. erinacei due to active growth of the fungus in the soil but passive transfer by contact with recently shed skin scales remains possible. The hedgehog population of New Zealand is very high... the animals are well known to have a predilection for gardens, and the average incidence of ringworm among them is $48 \%$ (English et al., 1964). The chances that children, especially, might contract the infection from this source are probably not inconsiderable'.

La Touche and Forster (1963) give special attention to the presence of mycelium in the quills of infected hedgehogs from the point of view of the facility with which infection could be transmitted to human beings handling these animals. Smith and Marples (1963) show the isolation of the fungus from quills and also discuss in a preliminary report the possible role of the hedgehog mite, Caparinia tripilis, in the transmission of the fungus from animal to animal. They note that hedgehogs in New Zealand do not harbour the flea Achraeopsylla erinacei which, though so conspicuous on animals living in Europe, was lost on its journey from this country to New Zealand, and is therefore not considered as a vector.

Though other authors have specifically mentioned the hazard of infection in children, of the three cases recorded here, only one is a child.

\section{CASE REPORTS}

CASE 1 A woman, aged 57 years, had an infection on the right hand, left side of the neck, and left axilla. She gave no history of contact with hedgehogs but handled a variety-of animals including mice, cats, and dogs. A mouse and cat were examined and found not to be infected but the dog was not examined (dogs may become infected by their natural curiosity or antagonism to hedgehogs).

CASE 2 A woman, aged 51, had blistering and peeling of the skin of the left hand. There was no history of contact with hedgehogs but she had contact with a dog with 'bad' ears. The dog was not made available for examination.

CASE 3 A boy, aged 6 years, had a plaque of healing erythema with a spreading edge on the left calf with satellite plaques. There was no history of contact with hedgehogs and only a vague contact with dogs.

In view of the suggested increase of infection by this fungus which may or may not be localized, a description of the colonial and microscopical picture is given.
TRICHOPHYTON MENTAGROPHYTES VAR. ERINACEI

On Sabouraud agar, with or without added chloram phenicol and cycloheximide, the colony grows rapidly with a central umbo, finely granular surface and fringed sub-surface border. A brilliant yellow or yellow-orange pigment is produced. Though the growth is rapid at $26^{\circ} \mathrm{C}$., optimum temperature is quoted as $35^{\circ} \mathrm{C}$. and growth is inhibited at $p \mathrm{H} 4 \cdot \vec{\oplus}$ (Smith and Marples, 1963); this is at variance with other $T$. mentagrophytes varieties.

Microscopically, microconidia are numerous macroconidia are often formed, and intermediate. forms are prominent. Spiral hyphae are rarelf produced (La Touche, 1965).

Our observations have shown the microconidia to be elongated and borne individually along the hyphae, not en grappe, and the hyphae show marked tendency to be straight or angular.

Murray (1964), doubted whether the organisno should be classified as a variety of $T$. mentagrophyte owing to the many differences observed, particularly mentioning the lack of spiral hyphae, later recognize as only rarely produced. The variation of optimum temperature for growth, and growth inhibition a甲 pH 4.0, quoted by Smith and Marples (1963), an the observation of the shape of the microconidie and attachment to the hyphae and the marke tendency of the hyphae to be straight or angularo together with other differences, including the pigment, supports this fact. The name Trichophyto $\overrightarrow{7}$ erinacei is proposed as being taxonomically more correct.

I wish to thank Dr. D. J. H. Payne, Director of the Public Health Laboratory, Portsmouth, for encourage 3 ment to publish this paper, Dr. I. G. Murray, Director of the Mycological Reference Laboratory, for identification and confirmation of the fungus strains and also valued help in preparing the manuscript, and Dr. A. Aitken Ross? consultant dermatologist, Portsmouth and Isle of Wight Hospital Groups, for giving clinical data.

\section{REFERENCES}

Eddowes, A. (1898). Trans. derm. Soc. G.B.I., 4, 32.

English, M. P. (1964). N.Z. med. J., 63, 586. $\longrightarrow$, Evans, C. D., Hewitt, M., and Warin, R. P. (1962). Brit. med. JV

Smith, J. M. B., and Rush-Munro, R. M. (1964). N.Z. med. J. 63, 40.

La Touche, C. J. (1965). Sabouraudia, 4, 69.

, and Forster, R. A. (1963). Ibid., 2, 143

Marples, M. J., and Smith, J. M. B. (1960). Nature (Lond), 188, 867

Murray, I. G. (1964). Bull. Hyg. (Lond.), 39, 1081

Smith, J. M. B., and Marples, M. J. (1963). Sabouraudia, 3, 1. 